\title{
Challenges or survival instinct of Tibetan entrepreneurs
}

\author{
Vedapradha. R and Hariharan Ravi \\ Department of Commerce and Management, St. Joseph's College of Commerce, \\ Bangalore, India
}

\begin{abstract}
Purpose - The purpose of this study is to explore the financial sources and evaluate the credit facilities available to Tibetan entrepreneurs especially residing in the vicinity of the Karnataka district, India. The most significant problem is that lending rates are extremely high and there is a lack of professional skill to manage their operations. Availability of financial support is still a major barrier for established and potential Tibetan entrepreneurs in the growth of their enterprises.

Design/methodology/approach - A sample size of 115 respondents, belonging to the urban and rural districts of Karnataka were interviewed to collect the information as primary data. Correlation analysis, cluster analysis, one-way ANOVA and percent test have been applied for statistical analysis. The interest rate, bank loan, credit, savings, friends and relatives, corporate, retained profits and trade credit are the variables used for the research.

Findings - Personal savings, bank credit and bank loans are the most important variables reflecting the credit activities and are clustered having a total of 3.710. Corporate, trade credit and retained profits form minimal sources of credit having a total of 1.194. Hence, there is an important relationship between the variables and the credit facilities availed by the entrepreneurs.

Originality/value - The research emphasis on their credit facility, financial growth, availability of capital are some of the challenges encountered by the entrepreneurs hindering the growth of the new business. Hence the researcher has focused on understanding and exploring the various challenges faced by these entrepreneurs.
\end{abstract}

Keywords Refugees, Financial support, Special economic zone, Technopreneurs,

Tibetan settlement

Paper type Research paper

\section{Introduction}

Entrepreneurship is the act of creating a business while building and scaling it to generate a profit. India has been an entrepreneurial society and has the skillsets. Entrepreneurship has been embedded in the Indian genes and is a part of its tradition. According to the research study conducted by NCAER (1993), lack of training and finance are the major problems faced by Small Scale Industries (SSIs) besides procedural hassles, administrative hurdles, lack of infrastructure and counseling (Santoro et al., 2007). Bangalore with salubrious climate has been a major attraction for the Tibetan Diaspora members of Tibet, who settled

(C) Vedapradha. $\mathrm{R}$ and Hariharan Ravi. Published in Asia Pacific Journal of Innovation and Entrepreneurship. Published by Emerald Publishing Limited. This article is published under the Creative Commons Attribution (CC BY 4.0) licence. Anyone may reproduce, distribute, translate and create derivative works of this article (for both commercial and non-commercial purposes), subject to full attribution to the original publication and authors. The full terms of this licence may be seen at http://creativecommons.org/licences/by/4.0/legalcode

The data collection for the research was supported by Penpa Lhamo. The authors would like to thank all the people who supported in accomplishing the research.

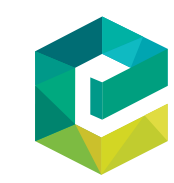

Received 30 November 2018

Revised 23 March 2019

10 June 2019

17 June 2019

Accepted 17 June 2019

instinct of

Tibetan

entrepreneurs

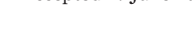


APJIE 13,2 in various colonies of Karnataka, attracting towards both education and employment. In the early 1970s, there were around Tibetan from various southern Tibetan settlements doing sweater business in Bangalore (Santhi and Kumar, 2011). This reduced from the 1990s due to various reasons as many of them went abroad, shifted to other occupations on their own. There is a new wave of entrepreneurship activity among the Tibetan Diaspora in the last ten years in Bangalore at present due to successful Tibetan entrepreneurs. Presently, 40 families are engaged in sweater selling business and 15 families into hoteliers in Bangalore. Most of the Tibetan entrepreneurs have installed their outlets and restaurant in the central and southeastern part of Bangalore, namely, Koramangala, Shivajinagar, Shanthinagar and Brigade road.

Bylakuppe is the oldest and largest group of Tibetan settlement in Karnataka, who were initially two families which later grew into a large township of Tibetans. This township attracts both local and foreign tourists. Shopping complex comprises of traditional Tibetan handicrafts like jewelry, bags, carpets and shawls, restaurants and hotels. The success of the Tibetan restaurants shows that Indians have good taste buds for new food. It also reflects that India can be a destination as a prospective business arena for a migrated community.

The purpose of the study revolves around the evaluation and exploring the probable and suitable financial resources to the prospective entrepreneurs residing in the vicinity of the state considered for the research. Most of the entrepreneurs are deprived of financial assistance for carrying out their traditional business due to lack of education, schemes and provisions offered by the government and illiteracy. It also includes the awareness of the respondents, their reaction and response towards the various financial assistance availed by them to ensure the sustainability of their business.

The Challenges encountered by the respondents were evaluated considering the business location based variables namely interest rate growth, collaterals, legal process, duration of finance, adequate funding, repayment of loans, raw materials, availability of labor, inadequate credit, technology, competition and fall in demand.

Indian economy promotes budding entrepreneurs that can reflect as a panacea to address major problems of employment and poverty. The Government of India has always thrived to cater to the need of the self-employment personnel like Industrial Policies and Five Year Plans specifically focusing on the growth of the small-scale sector, setting up of Special Economic Zones (SEZs), incubation centers, educational institutions exclusively for entrepreneurs, and financial support schemes for the promotion of entrepreneurship. Most the entrepreneurs face challenges and problems due to lack of availability of finance, technical knowledge, managerial skills, availability of resources and infrastructure, awareness about entrepreneurship schemes and regulatory framework, market linkage, etc. which obstruct the growth and development of the entrepreneurship in the country. Lack of training and finance are the major problems faced by Small Scale Industries (SSIs) besides procedural hassles, administrative hurdles, and lack of infrastructure and counseling. Vasper also found that there are many obstacles that affect entrepreneurship and identified a lack of seed capital as one of the major barriers. The Government of India has initiated many policies and developed schemes to facilitate the business that has led to an extraordinary improvement in recent years. India has evolved as the promising country for promotion of artic rafts and handicrafts.

\section{Theoretical background}

India has been the most sought nation to the refugees hailing from other neighboring nations such as Bhutan, Pakistan, Bangladesh and Nepal, as the nation has always opened 
its arms wide to the people looking for hope of survival acceptance by the local citizens. The country has focused on upbringing the talent especially in the small and medium scale business which has the support from the government as well. It has a rich heritage of culture, tribal arts, handicrafts, traditional handmade articles that can be of high exportable quality. This workmanship also attracts tourists drawing their attention towards the handmade articles, ancient arts carried forward generations after generations with an intention of retaining the culture and also promoting their business for livelihood. Some of the folk and tribal arts carry religious faiths creating an aesthetic value based on a certain belief system of the people. The development of any nation lies in the efforts undertaken to retain their ancient and rich cultural aspects held always high. Tibetan refugees who had migrated to India comprises of very small family size, looking for making their survival away from their native. The study reveals that Belgium entrepreneurs are more successful in developing their business in large-scale operations especially by the small firms due to the fact they have an entrepreneurial family background (Donckels and Dupton, 1986). Researchers have opined that financial systems enable in evaluating the probable entrepreneurs who can mobilize savings, improving the productivity based operations, diversifying the associated risks through innovations which also promotes an increase in profits if endogenous growth models are adopted in the business (King and Levine, 1993). Nigerian banks were reluctant in funding small and medium enterprises, stringent monetary policy and financial instability resulted in the credit crunch affecting the development of entrepreneurs (Ogujiuba et al., 2004). A small and medium sector can facilitate the overall development of the capabilities of the entrepreneurs through transitional literature (Aidis and Sauka, 2005). Entrepreneurship, business knowledge, and skills within micro and small businesses play an important part in the economies of countries across the globe by being the drivers of economic growth, as well as creating employment (GRAAF, 2007). Financing constraints are one of the leading challenges faced by the entrepreneurs across the globe that have to be addressed by the economic policymakers by empowering them with suitable and affordable financial sources to incept and develop their business (Kerr and Nanda, 2009). The rapid growth of young firms during various stages of entrepreneurship: This paper aims to examine factors influencing the high growth of new firms in metal-based manufacturing and business service firms in Finland. It seeks to compare the factors of how new firms achieve a high rate of growth during the first four years and years five to eight (Littunen and Niittykangas, 2010).

Pioneer entrepreneurs always stay focused, passionate by exploring various opportunities and converting their weakness into strength, and thrive to improve their abilities and are very resourceful (Santhi and Kumar, 2011). The researcher has attempted to emphasize the impact of microfinance contributing to the entrepreneurial development of small-scale enterprises in Nigeria and its global significance. Microfinance institutions operating in Nigeria are identified as the key players in the financial industry hampering the individuals, business organizations, other financial institutions, the government and the economy at large scale through their stringent services (Osunde and Mayowa, 2012). Social entrepreneurs are those individuals primarily focusing on addressing the social problems and affecting the social well-being with potential qualities of offering creative solutions with great zeal and persistent (Sivathanu, 2013). The author has stressed the importance of the Tibetan community playing a pivotal role in the growth of modern enterprises in sustaining the legal and political hurdles (Rigzin, 2014).

Tibetans in exile in India showcase their entrepreneurial spirit at the Tibetan Entrepreneurship Conference: On August 14, 2015, Your Story to the first-ever Tibetan Entrepreneurship Conference. A Two-day event that would bring together entrepreneurs,

\section{Survival instinct of Tibetan} entrepreneurs

205 
APJIE 13,2

government officials and the youth from the Tibetan community in exile in India (Mehta, 2015). India is one of the destinations for the Tibetan community to venture into small businesses exploring the various avenues in setting a strong base. The society promotes the development of this community by encouraging them to attend various training program (Yee, 2016). Tibetan refugees to American entrepreneurs: Sharing their culture and making a good living doing it is nothing new to Lhakar Dolma and her parents, Sonam Gyaltsen and TseringKyizom - the family has been selling goods from their native Tibet for the past decade and a half in Santa Fe, New Mexico (Inklebarger, 2017).

\subsection{Conceptual framework}

The entrepreneurs must be fueled with timely financial support to engage them in running the business successfully and for long sustainability. Finance plays a very pivotal role in effectively managing various resources. These refugees are primarily focused on direct selling and setting up roadside stalls to promote their products and intend to increase their sales as well. The existing cycle of their business comprises of obtaining financial assistance from credit and other sources. This engages them in making their potential products that are ready for sales. The revenue generated from the sales must be catered to meet their financial charges and expenses to run their families.

\subsection{Proposed promotion of business}

The entrepreneurs must adopt a simple but yet effective form of business models to expand their operations and enhance their sales. The conventional style of business may not fetch much revenue to their talent and hard work. The community is migrated and hence people may not be willing to improve their standard of living. Some of the promotional activities that can help these migrants to improve their sales and create a market can be as below. They must get in touch with local NGO's, rotary club or any other social concern organizations to help them in creating a larger market for their products rather than just confining to few places in Bangalore. Corporate firms can adopt this community through corporate social responsibility and help them to learn basics strategies of the business, set up stalls during any of the events at their campus on special occasions, donate funds to set up retail outlets, many more. The community must seek the help of the government to establish a venue to market their products during any exhibitions, stock clearance sales, promote their products during any local public events through constructive networking skills. The migrants can seek help to be associated with local talent groups to set up a coaching class to train youngsters, children and any interested public to learn their ancient and traditional arts so that it can help them creating better markets as well generate revenue. They must look for creating a market for their products online in association with some social networking sites and promote during the local cultural festivals.

\subsection{Proposed sources of funds}

The ancient culture and heritage must always be protected which serves as a platform in retaining the value system, beliefs of the community at a larger scale. The current model of business followed by these migrants is very limited in scope for the expansion of business and longer sustainability. Hence, the proposed model can adopt innovation to promote better. It is one of the most common and popular of recent times in seeking help from different groups to assist in offering financial support for the business. Some of the high net worth individuals who belong to a retired group, the aged group would always want to help people in need to develop their small scale business. These are opportunities for the community where different events held on special occasions will look for the potential 
entrepreneurs who can create a mark for their business sponsored by these incubators. Small business administration is one of the leading sources of financial support especially focused on the small-scale business owners extending their assistance to provide financial support without complicated legal formalities.

\subsection{Economic development}

Entrepreneurs are those business leaders always thriving towards the generation of ideas and focusing on nurturing the same in economic growth and development. Key areas that facilitate in the economic development can be discussed as below with special reference to the Indian economy. Capital Formation is created in pooling of the savings of the people by the entrepreneurs who facilitate in promoting capital formation by adding value to the economic and industrial progress. Unemployment is one of the leading issues in an emerging nation like India which can be addressed by offering job opportunities to various levels from artisans to technicians so earn their living. Regional disparities can be curbed by promoting balanced regional development through business set-up in the special economic zones and backward areas that offer benefits to the public in the form of transportation, education, health, etc. People from slums can get exposed to improvement in their standard of living. It facilitates the equal distribution of wealth, improves the standard of living, and increases per capita income for the development of society by reducing the concentration of income and wealth. Entrepreneurs, especially in the area of artisans and craftsmanship have an advantage in promoting the nation's culture and heritage that always creates a better overseas trade increasing the scope for foreign trade through exports. It serves as a Catalytic agent for the business set -up by the entrepreneurs stimulates industrialization, creating demand for the supplement units that encourage in supporting the economic growth, employment and overall economic development as it connects the various groups of the economy as an agent. Increase in exports promotes the generation of inflow of the foreign currencies, adding more reserves to the nation. Rural and remote areas are always neglecting during the process of economic development due to lack of infrastructure, qualified employees, scarcity of resources, etc. However, the entrepreneurs encourage active participation of these neglected people to be self-employed to develop their community by improvement in health care, education, training and transportation.

\subsection{Application of technology}

Trello: It is a free project management tool that ensures effective organization of the business by offering various facilities like e-book, e-mails and e-cards with a specific project. Google Docs: This tool eases the person to work on a file with multiple people and easily shared, collect responses through a questionnaire, chatting at the same time, etc. that can be customized as per the needs of the owner. Asana: It is the most prominent facility of realtime integration of teamwork. Dropbox: It is a digital space that can provide awesome plugin apps to improve the experience that facilitates easy access to the files from anywhere at any time. Slack: It is a chat app that serves as a communication tool for teams based on smooth design. Several channels can be created to discuss as either a group or private. The files can be easily shared and archived with messages, notifications. All the devices are automatically synced and can be connected with multiple devices. Momentum: The homepage of the devices can be changed with this app designed to inspire the team when the user browses, greeting the user by their name and picture. Spotify: This is a music app that helps the user to stay focused throughout their day of work which can be played on the integrated devices. 7-Minute workout: It can ensure the shedding of calories during the work with just the help of a chair and wall either at home or office. Boomerang: This is an

\section{Survival instinct of Tibetan} entrepreneurs 
APJIE 13,2

excellent app to manage emails where messages can be temporarily removed from the inbox, archived and then retrieved later at the convenience of the user. Emails can be scheduled with timings and date to be sent in the future. Voila Norbert: It is an app which locates the right email addresses when they are not on the list of the website based on the names of the lists of officials in the company. Sidekick: It is an email add-on that provides the information related to recipients of those emails regarding the timings, location when they read the emails. 99 Designs: It is an app that facilitates the user to customize their logo and themes for the product and services offered and the decision can be made after experiencing the results. The designers across the globe will support in creating the designs, which later can be chosen by the user. Canava: This tool is useful in designing the graphics serving as a platform allowing the user to be the designer himself in the form of artwork on the websites. very: It is an innovative tool for users at a very economical price offering designs, business cards, writes messages, translations, etc. Clarity FM: Community experts provide services to the users at the convenience of the user based on the customized queries. Typeform: It is a tool to conduct effective surveys by the users that enable in giving feedbacks from the readers, customers, etc.

\subsection{Scope for further research}

The study can be conducted in detail by increasing the size of the sample for better data accuracy and the results of the research. There is increasing knowledge, awareness of the schemes, empowerment of entrepreneurs, due to which the country is expanding the boundaries opening its arms towards the youngsters to step forward in venturing into entrepreneurship. This can be focused on the various start-ups initiated by these youngsters. Similar studies can be conducted across other states in India.

\section{Empirical research}

\subsection{Research model}

The geographical coverage of this survey belongs to major Tibetan settlements of both urban and rural in Karnataka state namely Bylakuppe, Mungod, Hunsur, Kollegal and Bangalore. The respondents have limited due to the small size of their families migrated to India are still on the process of settling down and creating a mark for themselves. Regarding the research survey on Tibetan entrepreneurs, so far there are few researchers who have emphasized on the developmental of entrepreneurship in the Tibetan exile community and its impediments to the growth of Tibetan entrepreneurial in India. Hence, this highlight of previous research surveys has not covered an extensive study on the obtaining of credit and financial constraints of an entrepreneur. The refugee Tibetan entrepreneurs have great potential in flourishing their culture and craftsmanship in the nation to promote their ancient heritage, earn for survival, and expect to provide education to their children. They are very determined to create an environment for themselves along with their community, capable enough to develop their business with a hope of protection from being exploited and preventing from the involvement of any illegal activities. However, even a small-scale business requires minimum financial support in recovering the cost incurred and for marginal profit earnings. Hence, the researcher has attempted to assess the feasibilities of obtaining such financial support from various sources to sustain in the business, as the refugees have no collaterals. The objectives of the study consist of assessing the financial and credit facilities availed by the respondents to operate the business and challenges encountered by them. The whole analysis for this present study depends on primary sources which are collected with the help of the structured questionnaire prepared and direct interviews to define information from the samples chosen from Tibetan entrepreneurs who 
voluntarily participated in the study. Convenience sampling technique has been applied in the study. Secondary data has been obtained from the reports and publications of Government websites. However, secondary data have been collected from the official websites of the government. Some of the respondents have not maintained the records for the business operated by them due to the lack of awareness with regard to accountancy and few were not educated and hence they were reliable on the educated family members to provide the information. Statistical Package for Social Science (SPSS) is the statistical tool used for testing descriptive statistics, one-way ANOVA (Analysis of Variance), correlation analysis and cluster analysis. The current study is confined only to the evaluation of the financial sources and other credit facilities required for the Tibetan entrepreneurs to operate and sustain in the business. There is scope for further research of comparative study of performance in business before and after obtaining financial support, any financial grants or subsidies obtained by the state government, measures and schemes introduced by the state government for the empowerment of these refugee communities, training and development programs, workshops conducted, etc.

\subsection{Hypothesis}

H01. There is no significant relationship between the variables that are chosen for the analysis.

H02. There is no significant difference between business location and challenges faced.

\subsection{Reliability analysis}

The results based on the reliability test using Cronbach's Alpha have been shown in Table I. The coefficient alpha $(\alpha)$ of the eight items is 0.832 , which reflects the reliability of the given factors. The items chosen proves to be statistically significant as the $(\phi<0.01)$ at 0.01 per cent level.

\subsection{Adequacy and validity analysis}

The sampling adequacy and test of Sphericity have been performed to the resultant correlation matrix to test whether there is any relationship between the variables with significance or not. Table II shows that there is a significant relationship among the variable chosen as the " $p$ " value is less than 0.000 ( 0.001 per cent level). Adequacy test yielded a KMO result of 0.810 which states that Correlation Analysis can be carried out appropriately for

\begin{tabular}{lccc}
\hline No of items & Cronbach's alpha & F & Sig \\
\hline 8 & 0.832 & 19.554 & 0.000 \\
\hline
\end{tabular}

\section{Survival instinct of \\ Tibetan}

entrepreneurs

209

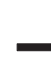


APJIE 13,2

\section{0}

these variables which are also significant at 0.001 per cent level. Hence, the null hypothesis is rejected and the alternative accepted.

\subsection{Correlation analysis}

The technique applied in this study reflects the respondent's level towards the source of credit in order to run the business. The factors responsible for sources of credit are B1, B2, B3 ...B8 is given in the below.

\subsection{Factor analysis}

The principal component analysis and the rotated factor loading method have been used to understand and evaluate the stimulating factors. From Table III, it is observed that out of eight factors, two-factor values, namely, credit activity and other financial sources, are identified by the rotation method. The total percentage of variation in the factors shows 61.3 per cent.

\subsection{Cluster analysis}

Table IV depicts the clustering of stimulating factors showing the level of Tibetan Entrepreneur towards the source of credit in order to run the business broadly grouped into credit activity and other financial sources. The variables personal savings (B1), bank credit (B2), Friends and relatives (B3), Bank loans (B5), and TED, CTA (B8) are clustered together as factor 1 forming the components of "credit activity "and have a total of 3.710. The next three variable Corporate (B4), Trade credit (B6), Retained profits (B7) are constituted as factor 2 forming the components of "other financial sources "and have a total of 1.194.

\begin{tabular}{lcc}
\hline Particulars & Factor (1) & Factor (2) \\
\hline Personal Savings (B1) & 0.648 & 0.161 \\
Bank Credit (B2) & 0.809 & 0.229 \\
Friends and Relatives (B3) & 0.645 & 0.360 \\
Corporate (B4) & 0.223 & $\mathbf{0 . 8 0 9}$ \\
Bank Loans (B5) & 0.819 & 0.191 \\
Trade Credit (B6) & 0.247 & 0.826 \\
Retained profits (B7) & 0.155 & 0.817 \\
TED, CTA, etc. (B8) & 0.592 & 0.089 \\
Total & 3.710 & 1.194 \\
\hline
\end{tabular}

Table III.

Rotated factor loading on the financial sources of credit

\begin{tabular}{llc}
\hline Factors & Particulars & Rotated factor loadings \\
\hline 3.710 & Personal Savings (B1) & 0.648 \\
(Credit Activity) & Bank Credit (B2) & 0.809 \\
& Friends and Relatives (B3) & 0.645 \\
& Bank Loans (B5) & 0.819 \\
1.194 & TED, CTA, etc. (B8) & 0.592 \\
(Other Financial Sources) & Corporate (B4) & 0.809 \\
& Trade Credit (B6) & 0.826 \\
& Retained profits (B7) & 0.817 \\
\hline
\end{tabular}


Sources of credit required to run the business stimulate the level of Tibetan entrepreneur are influenced by the factors comprising of corporate, trade credit, and retained profits.

\subsection{One-way ANOVA}

Table $\mathrm{V}$ shows the business location and challenges faced by the respondents towards obtaining credit and financial growth. The F value at 0.074, 0.006, 0.087, 0.017 and 0.020 . Since the $\mathrm{F}$ value is significant in the above mention at 5 per cent, 10 per cent and 1 per cent levels, This shows that majority of the respondents are faced a challenge in interest rate too high, lengthy process and complex, provide sufficient funding, labor trouble, and inadequate credit respectively. Hence, the null hypothesis is rejected and accepted the alternative hypothesis that there is a significant difference between the location of business and challenges faced by the respondents. One -way ANOVA was performed to analyze the statistical differences associated between and within the groups of the business location and financial growth. It resulted that there is statistically significant evidence with regards to the legal formalities $(\mathrm{F}=3.803, p<0.01)$, availability of labor $(\mathrm{F}=3.160, p<0.05)$, and inadequate credit supply $(\mathrm{F}=3.064, p<0.05)$.

\section{Conclusion}

Entrepreneurship enhances economic development by creating new job opportunities, improves skillsets, and contributes to GDP, increases exports, the standard of living. The attempt of the author focuses to understand the challenges of Tibetan entrepreneurs in obtaining credit and financial growth in Karnataka state. These entrepreneurs are not much dependent on accessing credit from the bank, as their source of finance is informal through friends and relatives. Correlation Analysis reflects the source of credit that depicts clustering of stimulating factor in the level of Tibetan Entrepreneur towards the source of credit in order to run the business. Variables B1, B2, B3, B5, and B8 are clustered together as factor 1 and are named as "credit activity "and have a total of 3.710. The next three variables B4, B6, B7 are grouped as factor 2 and is named as "other financial sources "and have a total of 1.194. Hence, the results show a significant relationship between the variables. One-way ANOVA resulted in confirming the statistical significance of the business location based parameters chosen for the study had a strong difference in variance while checked for within and between the population and the sample chosen for the study. Therefore, Legal process, availability of labor, and inadequate credit plays a pivotal role in channelizing the financial credit towards the entrepreneurs based on the location of their business. The process of

\begin{tabular}{lcccr}
\hline Challenges & F-value & SIG. & \\
Interest rate growth & 2.197 & 0.074 & \\
Collateral & 1.028 & 0.396 & $(0.006) * * *$ & Table V. \\
Legal process & 3.803 & 0.676 & Challenges of \\
Duration of finance & 0.582 & 0.087 & entrepreneurs \\
Adequate funding & 2.090 & 0.510 & between and within \\
Repayment of loans & 0.828 & 0.561 & $(0.017) * *$ & the groups of \\
Raw materials shortage & 0.748 & $(0.020) * *$ & business location \\
Availability of labor & 3.160 & 0.131 & towards obtaining \\
Inadequate credit & 3.064 & 0.437 & credit and financial \\
Technology & 1.813 & 0.103 & growth \\
Competition & 0.953 & 1.976 & &
\end{tabular}


complete the document verification, submitting of legal documents is very time consuming for these businessmen who are not educationally qualified. The other business locationbased variables are proved statistically not significant in deriving the challenges encountered by the respondents in availing the financial credit and support.

\section{References}

Aidis, R. and Sauka, A. (2005), "Entrepreneurship in a changing environment: analyzing the impact of transition stages on SME development", in Welter, F., Challenges in Entrepreneurship and SME Research. European Council for Small Business and Entrepreneurship (ECSB), 2nd Inter-Rent Online Publication, pp. 5-35, available at: www.ecsb.org/wp-content/uploads/2014/06/interrent_2005.pdf and www.ecsb.org/wp-content/uploads/2014/06/inter-rent_2005.pdf\#page=9

Graaf, R. (2007), The Extent of Entrepreneurship, Business Knowledge and Skills within Micro and Small Businesses on the Mid-South Coast of Kzn, Doctoral dissertation, available at: http://openscholar. dut.ac.za/bitstream/10321/417/1/Graaf_2007.pdf

Kerr, W. and Nanda, R. (2009), Financing Constraints and Entrepreneurship, Cheltenham, available at: www.nber.org/papers/w15498

King, R.G. and Levine, R. (1993), "Finance, entrepreneurship, and growth, theory and evidence*", Journal of Monetary Economics, Vol. 32 No. 3, pp. 513-542.

Littunen, H. and Niittykangas, H. (2010), "The rapid growth of young firms during various stages of entrepreneurship", Journal of Small Business and Enterprise Development, Vol. 17 No. 1, pp. 8-31.

Mehta, J. (2015), Tibetans in Exile in India Showcase Their Entrepreneurial Spirit at the Tibetan Entrepreneurship Conference, Dharamsala, available at: https://yourstory.com/2015/09/tibetanentrepreneurship-development

Ogujiuba, K.K., Ohuche, F.K. and Adenuga, A.O. (2004), "Credit availability to small and medium scale enterprises in Nigeria: Importance of new capital base for banks-background and issues", Central Bank of Nigeria Bullion, Vol. 28 No. 4, pp. 52-69.

Osunde, C. and Mayowa, A.G. (2012), Microfinance and Entrepreneurial Development in Nigeria, Jorind, Vol. 10 No. 3, pp. 405-410.

Rigzin, T. (2014), Fostering an Entrepreneurship Environment in Exile, Atlanta, available at: www. phayul.com/news/article.aspx?id=35561\&t=1

Rigzin, T. (2014), The Impediments to Tibetan Entrepreneurial Growth in India, Atlanta, available at: www.tibetanreview.net/the-impediments-to-tibetan-entrepreneurial-growth-in-india/

Santhi, N. and Kumar, R.S. (2011), "Entrepreneurship challenges and opportunities in India”, Industrial Engineering and Management Science, 14-16.

Santoro, M.D., Bierly Iii, P.E. and Gopalakrishnan, S. (2007), "Organisational learning from external sources: new issues and performance implications", International Journal of Technology Management, Vol. 38 Nos 1/2, pp. 1-10.

Sivathanu, B. (2013), Challenges For Social Entrepreneurship, New Pune.

Yee, A. (2016), India Offers Training, Funding to Spur Growth in Tibetan Entrepreneurs, available at: www. voanews.com/east-asia-pacific/india-offers-training-funding-spur-growth-tibetan-entrepreneurs

\section{Further reading}

Abdulkadir, F.I., Umar, S. and Gar, B. (2013), The Impact of Micro-Finance Banks on Women Entrepreneurial Development in Metropolis, Nigeria.

Basha, M., Pranav, S.K., Rao, N. and K, M. (2013), "A study on the development of women entrepreneurship in Nellore, AP, India”, Management Sciences, pp. 1-5. 
Bassetto, M., Cagetti, M. and Nardi, M.D. (2015), "Credit crunches and credit allocation in a model of entrepreneurship", Review of Economy Dynamic, Vol. 18 No. 1, pp. 53-76.

Batthini, G. (2009), Research in Entrepreneurship: doctoral Dissertations in India during 2000-2008, Gandhinagar.

Bawaneh, S.S. and Al-Kayyali, A. (2014), "Financial issues facing entrepreneurs", Empirical Finance, pp. 97-103.

Banerjee, A., Breza, E., Duflo, E. and Kinnan, C. (2015), Do Credit Constraints Limit Entrepreneurship? Heterogeneity in the Returns to Microfinance, Columbia.

Cho, Y.H. and Lee, J.H. (2018), "Entrepreneurial orientation, entrepreneurial education and performance", Asia Pacific Journal of Innovation and Entrepreneurship, Vol. 12 No. 2, pp. 124-134.

Dai, N. and Ivanov, V. (2010), Entrepreneurial Optimism, Credit Availability, and Cost of Financing: Evidence from US Small Businesses, Albany.

Hassan, N.B., Chin, S.T. and Yeow, J.A. (2011), Financial Constraints and Opportunities of Micro Enterprise Entrepreneurs: A Theoretical Framework, Kuala Lumpur.

Inklebarger, T. (2017), Tibetan refugees to American entrepreneurs, Dolma, L. and Gyaltsen, S. Interviewers.

Kerr, W.R., Nanda, R. and Matthew, R.K. (2014), "Entrepreneurship as experimentation”, Journal of Economic Perspectives, Vol. 28 No. 3, pp. 25-48.

Kerr, W.R. and Nanda, R. (2014), Financing Constraints and Entrepreneurship, Boston.

Lelarge, C., Sraer, D. and Thesmar, D. (2007), Entrepreneurship and Credit Constraints, France.

Potabatti, P.S. and Bob, D.N. (2015), "Youth entrepreneurship: opportunities and challenges in India", Research and Method in Education, pp. 55-59.

Rigzin, T. (2015), A Survey Research on Tibetan Entrepreneurs in India, Atlanta.

Rigdol, T. (2016), A slice of Tibet at your doorstep. (K.S. Sebastian and Interviewer, ).

Corresponding author

Vedapradha. R can be contacted at: vedahariharan@gmail.com

For instructions on how to order reprints of this article, please visit our website:

www.emeraldgrouppublishing.com/licensing/reprints.htm

Or contact us for further details: permissions@emeraldinsight.com 